a White Rain- or Fog-Bow " (Quart. Fourn. Met, Soc., Octoiver I875). A. RAMSAY

A Nocturnal Hymenopterz of the Genus Bombus

Mr. Leonardo FEa, Assistant in the Museo Civics of Genoa, who is now engaged in a zoological exploration of Upper Burmah, and who has extensive experience in collecting insects, writes to me from Mandalay that, on the night of January 7 , as he was walking in the "compound" of Dr. Barbieri, the moonlight being very bright, he was surprised to hear humming around a clump of flowering acacias. He at once proceeded to fetch a net, and, on capturing the hummers, found, to his no small astonishment, that he had got a fine species of the genus Bombus, of a uniform fulvous colour.

Being unaware that the fact of a nocturnal melliphagous Hymenoptera (all of which are eminently diurnal) has been before noticed, I should be glad to hear of any other cases to the point.

Genoa, February 16

G. DORIA

\section{PHYLLOXERA AT THE CAPE}

$\mathrm{W}$

$\mathrm{E}$ have received from a correspondent in South Africa some details of the long-dreaded appearance of the Phylloxera in the vineyards of the Cape Colony. As long ago as 1880 the importation of living plants in any form or shape was forbidden by the Cape Government. This measure was so strictly enforced that consignments of young beech-trees from England and of tree-ferns from New Zealand were not allowed to be landed.

In 1884 the prohibition was for a short time relaxed. But it was speedily revived, under a penalty of $500 l$. or two years' imprisonment with or without hard labour in the case of any one infringing it.

The insect has now, notwithstanding, actually appeared in a few vineyards near Cape Town, and in two others about twenty-four miles off.

Fortunately the Cape Government has competent scientific advice at hand. Mr. Roland Trimen, F.R.S., the Director of the South African Museum, and a wellknown entomologist, attended the Phylloxera Congress at Bordeaux in $188 \mathrm{I}$ as the representative of the Cape Colony. A Commission to examine and report on the outbreak has been appointed, consisting of Mr. Trimen, of M. Péringuey his assistant, and of Prof. Macowan, F.L.S., Director of the Botanic Garden. M. Péringuey is a Bordeaux man and a good entomologist; he first drew Mr. Trimen's attention to some suspicious-looking mites on a slide which had been taken from a Cape vineyard by the doctor of a French ship, about Christmas.

Two or three of the vineyards are simply swarming with Phylloxera. But in others it appears to have only recent centres. Unfortunately sulpho-carbonates and carbon bisulphide are little more than names in th: colony, and it has been necessary to telegraph for a supply. Pending the arrival of the insecticide, the vines are being uprooted and burnt. The result so far is encouraging, and the small range of the insect leads to the hope that it may be well kept under if not stamped out.

\section{OSCAR SCHMIDT}

FDWARD OSCAR SCHMIDT was born at Torgau on February 2r, 1823. When he had finished his preliminary education he was sent to Berlin, where he had the advantage of studying natural history, to which his mind early had a bent, under the superintendence of Johannes Müller and Ehrenberg. Schmidt, however, proceeded to Jena to take his degree in 1849 , and he held the post of Professor of Natural History in the University until 1855. His "Manual of Comparative Anatomy," which went through several editions, was first published in 1849 . Appointed Professor of Zoology in the University of Cracow in 1855 , he was obliged, two years afterwards, to quit the country, owing to some unfortunate political complications, and he took refuge in Gratz. He was appointed Professor of Zoology and Comparative Anatomy in the University, and in time was made its Rector. During many of his vacation tours he visited the Ionian Islands and other places on the shores of the Adriatic, and, diligently working out the fauna of this almost tideless sea, he became more and more interested in the natural history of the Sponges, with the result that in $\mathbf{1} 862$ he published his well-known and important work, "Die Spongien des Adriatischen Meeres," to which two supplements were issued in 1864 and 1866 , followed in 1868 by a third supplement, which formed part of a new work on "Die Spongien der Küste von Algier." It will be conceded that this work of Schmidt's marked an epoch in the history of this interesting sub-kingdom. The enormous progress made in our knowledge of the natural history of the Sponges during the twenty-four years that have elapsed since Schmidt put forward his classification, and the immensely improved methods of research, may be said to have revolutionised the subject; but Schmidt's work will always be of value, and the merit of having grasped the leading features of the classification of the Sponges will generally be awarded to him. That he for the most part failed to perceive the proper specific and generic characters of the forms he describes and figures is not to be much wondered at. In 1870 , leaving the Sponge fauna of the Mediterranean, he published his "Grundzuge einer Spongien Fauna des Atlantischen Gebietes," which was followed in 1874 by an account of the Sponges collected by the German Expedition to the North Sea; and his latest contribution to this subject was his work on "Die Spongien des Meerbusen von Mexico, 1879-1880." In 1872 he was appointed Professor of Zoology to the University of Strasburg, returning thus once more to his fatherland.

Though his works on "The Natural Sciences and the Philosophy of the Unconscious" and on "The Descendance Theory of Man and Darwinism" passed through several editions, and were translated into French, they need not be more particularly referred to here. As already noticed in these volumes, Prof. Schmidt died at Strasburg on January I 7 last.

\section{THE STORY OF BIELA'S COMET'}

ISK you to listen to-night to the story of Biela's comet. I will weave into the story enough of astronomy to justify its place in this course as a lecture.

This story has none of the interest which human passions give to stories of human life, and yet if it shall not be to you as interesting as a novel, it will be because I shall spoil the story in telling it to you. It is a true story. In other words, I mean to separate sharply what we know from what we guess.

One hundred and two years ago last night (March 8, 1772) a Frenchman named Montaigne, in the provincial city of Limoges, found a comet. He did what little he could with his small telescope to mark its place in the heavens, but it was not much that he could do. The comet was a faint one, not to be seen by the naked eye, and had a short tail, only one-eighth as long as across the disk of the moon. He did not dream that that little foggy speck of light was to be one day one of the most interesting comets in the solar system; in fact, that he himself was to be known to history only for having first seen it. This little comet is the hero of my story-a hero from humble life. Montaigne wrote to Paris of his discovery, and they saw it three or four times before it disappeared.

I A Lecture delivered by Prof. H. A. Newton, on March 9, $18_{74}$, at the Sheffield Scientific School of Yale College, U.S. The renewed interest in Biela's comet created by the great shower of meteors on November 27 last justifies giving space for this lecture. From the American Joumal of Science. 
Thirty-three years later, November I805, another Frenchman, named Pons, saw the comet. It passed rapidly from the northern heavens, and in a month went below our horizon. It came this time very close to the earth, and I shall in a moment tell you how it appeared. It was visible to the naked eye, even in strong moonlight. Twenty years later, February 1826, an Austrian officer, Von Biela, again found the comet. So soon as an orbit could be computed, it was seen that the three comets of 1772 , 1805, and 1826 were the same body. This has since been known as Biela's comet. Its exact path around the sun could now be told. Let me show it to you.

Let us look down upon the solar system from a point several hundreds of millions of miles north of it. Looking southward we should see the sun in the centre. The earth, with its moon, would travel around the sun in a path or orbit denoted by the circle in the figure (Fig. I).

It goes about the sun once a year, being, on the Ioth days of January, April, July, and October, at the points so marlied on the diagram. The motion is opposite to that of the hands of a watch. Outside, five times as far from the sun as is the earth, will be the huge planet Jupiter, a part of whose path you see. It goes about the sun once in twelve years. The paths of the other planets are not in the figure, as I have nothing to say about them to-night. In the figures which I show you the earth's orbit is twenty inches in diameter, or one inch to nine million miles. An express railway train travelling all the time for a fortnight would pass over about the thousandth of an inch in this figure. 'The comet's path is the ellipse. Around this ellipse it travelled three times in twenty years, or once each $6 \frac{2}{3}$ years. When nearest to the sun, or at perihelion, it went within the earth's orbit, and when most distant it passed beyond Jupiter.

The comet's motion is very unequal. At $\mathrm{D}$ it moves very slowly. As it falls towards the sun the sun's attraction makes it move faster and faster, so that it whisks rapidly by $P$. As it then rises from the sun on the other side of the orbit, the sun not only turns it ever out of the straight path it would move in, but it stops its upward momentum, so that when it reaches $D$ again it has only its old velocity with which to repeat its circuit. At $P$ its velocity is twenty-eight miles, at $D$ four miles, a second. In fact, to pass over the part lying apparently outside of Jupiter's orbit, just half of the whole $6 \frac{2}{3}$ years is required. I said apparently outside, for another fact must be noticed: while Jupiter and the earth may be said to move in the same plane, that of the figure, the comet's orbit, lies at an angle. Suppose the ellipse to be a metal ring, and let it turn about the line $\mathrm{A} B$ as a hinge, the part $\mathrm{AD} B$ rising toward you, and the part A P D retreating from you. The parts near D must rise about the half-diameter of the carth's orbit to give the true position of the two planes. Notice that the comet's and the earth's orbits cut each other

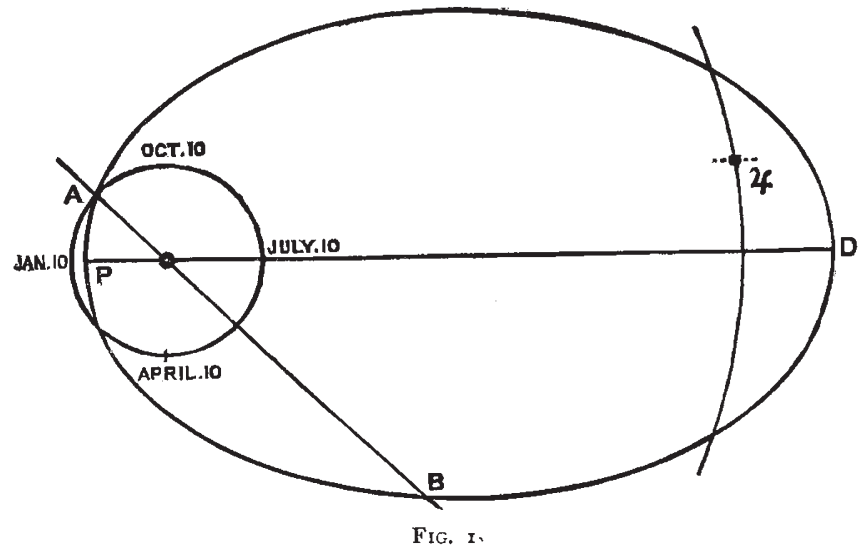

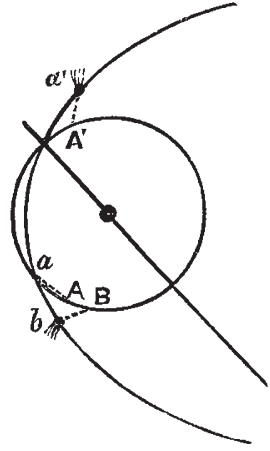

FIG. 2.

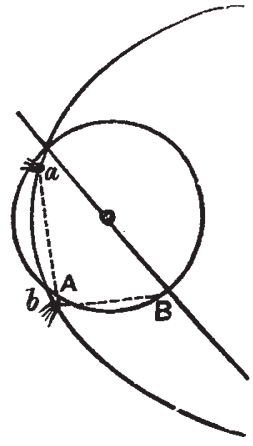

FIG. 3. at the node on the line A B. The importance of this fact will by and by appear. The two orbits seem to cut each other at another point (below P), it is true, but because of the angle of the planes the cutting is only apparent.

Like all other comets, this one was visible only when near the earth and near the sun. Through the outer part of its path it was never seen, even with a telescope. The comet was seen in 1826 for the third time.

Positions in 1772 and 1805 .- In March 1772 it was first seen from $\mathrm{A}$ in the direction $\mathrm{A} a$ (Fig. 2). It was last seen four weeks later from $B$ in the direction $B b$. In November 1805 Pons found it when the earth was at $A^{\prime}$ and the comet at $a^{\prime}$ (Fig. 2). Both the earth and the comet were going to the node, the comet going faster than the earth. The earth passed the node just ahead of the comet. I have told you that the comet was then visible to the naked eye even in moonlight, and well it might be. On December 8, with the scale of the figures before you, it was only $\frac{3}{8}$ th of an inch from the earth at the node. On the same scale the moon is $\frac{\mathrm{l}}{40}$ th of an inch from the earth. The comet passed $\frac{1}{15}$ th of an inch outside the earth's orbit, but the earth was already past that point.

Dr. Schröter describes the comet: To the naked eye it was (Dec. 8) a large round cloud of light nearly as large as the moon. In a 13 -foot telescope it had the same appearance, though it was much smaller, and it had a bright, star-like nucleus. The nucleus had not sharp edges, not even a definitely round form, but was like a light shining through a fog. Its diameter was about II 2 miles, or, if we take its central light, 70 miles; speaking roughly, as large as the State of Connecticut. The whole cloud, as seen in the telescope, was some 6000 miles in diameter; to the naked eye perhaps 30,000 miles. How much smaller than 70 miles was the hard part of the nucleus we cannot say.

Position in 1826 . - In 1826 it was first seen from $\mathbf{A}$ in the line A $a$ (Fig. 3). Astronomers followed it with care, as they had come to know that it was a comet of short period, and not many such were then known. Its path then crossed just inside the earth's orbit at the node, but only $\frac{1}{50}$ th of an inch in the diagram, or 20,000 miles, in fact, from it.

Position in 1832 . - Six and two-thirds years brings us to I832, and you can readily.imagine with what interest this first-predicted return was watched for. Some of you also remember the widespread, though groundless, fears at that time of a collision of the earth and the comet. The comet was first seen by Sir John Herschel in September. In his 20 -foot reflecting telescope he saw it pass centrally over a group of small stars of the 16 th or $17^{\text {th }}$ magnitude. The slightest bit of fog would have at once blotted out the stars. Through the comet, however, they looked like a nebula, resolvable, or partly resolvable, into stars. How thick the cometic matter was we do not know. Its extent 
laterally, was not less than 50,000 miles. Again, M. Struve saw it pass centrally over a star of the 9th magnitude. A like star was seen in the telescope at the same time, so that he was able to say that the comet did not dim in the least the one which it covered. The comet, as the figure (Fig. 4) shows, was in 1832 always at a great distance from the earth.

Another 62 years brings us to 1839 . The comet came to perihelion, at $\mathrm{P}$, in July. The earth and comet were on opposite sides of the sun both before and after July, and of course the comet was not seen.

Position in 1845 .- Another circuit was finished in $1845^{-6}$.

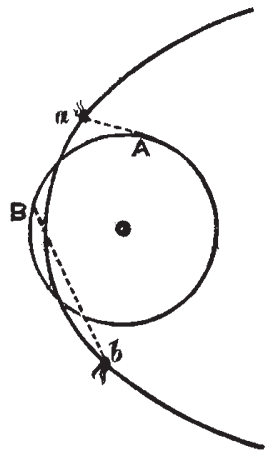

FIG. 4 .

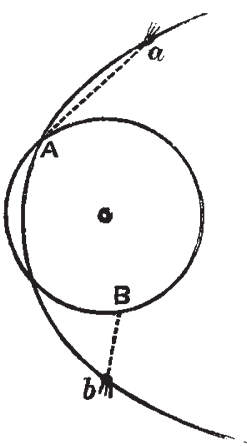

FIG. 5 .
The comet was visible then during five months, from $a$ to $b$ (Fig. 5), or as viewed from the sun through nearly half its circuit. At this time it was that the comet became all at once famous.

On December 29 Mr. Herrick (then Librarian of Yale College) and Mr. Francis Bradley (then in the City Bank) were watching the comet through the Clark telescope in the Athenæum tower yonder. They saw a small companion comet beside the larger one! What did it mean? Had the comet a satellite like the earth's moon? Or had the comet been split by some convulsion? Two weeks later the companion comet was seen by Lieut. Maury and

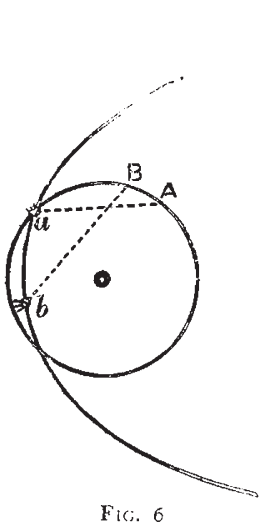

Fici. 6

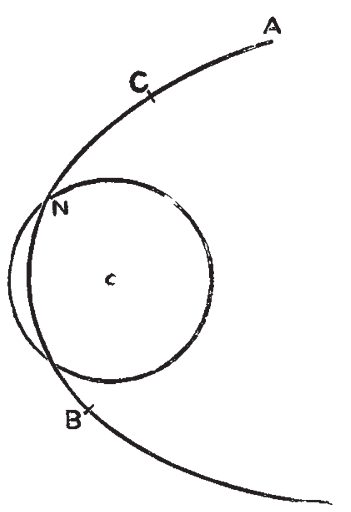

FiG. 7 .
Prof. Hubbard at Washington, and two days after that it was seen by two or three European astronomers.

Changes were seen in the larger telescopes that increased the mystery. The faint companion grew in size and brilliancy. Each comet threw out a tail. Then the smaller one had two tails. Then the larger one bad a pointed, or diamond-shaped, rather than a round head. Two nuclei were seen in the larger one, and it also had two tails. An arch of light was thrown over from one to the other. For some days in February the companion was the brighter of the two. Presently three tails were seen running from the primary, and three cometary frag- ments (one observer says five) around its nucleus. What could it all mean? Do you wonder that astronomers were excited by these wizard changes?

The companion comet was seen in Washington by Maury and Hubbard two weeks after it was seen here by Herrick and Bradley. Prof. Joseph Hubbard was the son of a resident of New Haven, well known to many of you from his connection with the New Haven Bank. Prof. Hubbard was graduated two years before (in 1843) at this College, and was now Professor in the Naval Observatory at Washington. He took up the study of the motions of the two Biela comets as special work, outside of his hours on duty. How faithfully he worked, four thick manuscript volumes of figures might tell. I cannot show you those books. They form, since Prof. Hubbard's death, a cherished memento in the possession of a friend. But I have brought another of Hubbard's volumes from the College Library, one of three upon the comet of I 843 , in order to show you by what patient labour some of the results of astronomy must be wrought out. In your school days you called it a wondrously long sum that covered both sides of the slate. On the leaves of this book there are, as you see, one, two, three, and in some cases, I think, even four thousand figures upon the page. You will, I am sure, excuse me from telling in detail to-night how we learn about the sizes, distances, and motions of the comets. Eight or ten such volumes of figures, to be increased in time, we hope, by the four Biela volumes, form a monument to a true, devoted, gentle scholar of science. You will not wonder when I tell you that he hated shams.

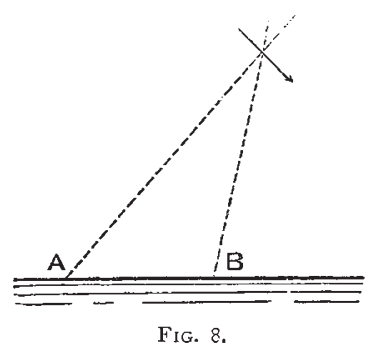

Position in 1852 . - In 1852 the comet was always at a great distance from the earth (Fig. 6), and only to be seen through the largest telescopes. The changes of size and brightness of the two comets were remarkable, and as they could but just be seen, sometimes one and sometimes the other alone was visible; which one it was that a person saw at any time was only told by computation afterwards.

The two comets were now eight or ten times as far apart as they had been seven years before. They were at the point P, I,250,000 miles apart. Prof. Hulbbard found that he could not tell which comet of 1852 was preceding and which following in 1845 . One supposition agreed as well with the observations as the other.

Perhaps the knowing ones among you have noticed that the arc from the node to the point marked Jan. Io in the first diagram is too large for one month, for in 1772 the earth passed the node Dec. 9. But you will notice that when the comet is at $\mathrm{D}$, and the large planet Jupiter is near by, he draws the comet toward the plane of the figure. The result is to bring the comet down to meet the earth's orbit farther from $P$. The node thus went back from Dec. 9 to Nov. 27, a distance of 12 days, or $12^{\circ}$ in the circle. 'The figure represents this last orbit. By the same cause the inclination was reduced one-fourth, or from $17^{\circ}$ to $12^{\circ}$.

Since September 1852 (with one doubted exception to be spoken of), neither of the two Biela comets had been seen. In I 859 their path was to us behind the sun. In I 866 they should have been at the point P on January 26. 
A better chance of seeing them could hardly be. They were at all times to be away from the sun's light, and when nearest to the earth not more than one-fifth the sun's distance. The paths were carefully computed, and the action of all the planets, notably that of Jupiter, allowed for. A dozen observers for months swept the heavens with their telescopes, but not the slightest trace of the comets was seen.

Again, they should have come to perihelion a year ago last autumn (Oct. 6, I 872), but, as 1 suppose, neither of them was seen. With the loss of its hero, our story would seem to come to an end. I must ask your indulgence, however, for another chapter.

I suppose that each one of you has often seen a shooting-star. On a clear night you have seen a bright point of light travel quickly across the sky, as though a star had been shot from its place in the firmament. It may, if it was a large one, have broken into sparks as it disappeared, or have left a cloudy train along part of its path for an instant; or perhaps it was so faint even that you could not be quite sure that you saw anything. Some of you have seen those shooting-stars by hundreds in star showers.

Until near the clese of the last century, poets dreamed, and other men guessed, about these objects, but knew nothing. Two German students, Brandes and Benzenberg, found out, and told us, that these bright flights were in the upper parts of the atmosphere. From the two ends of the city a track always appeared to be in the same part of the heavens. But when one went to a village many miles away, a track was seen by the two persons (at $\mathrm{A}$ and B, Fig. 8), in different parts of the sky. Hence they were able to measure the height of the shooting-stars from the ground.

We now know that these luminous paths are rarely less than 40 miles or more than 90 miles from the earth. We also know that any shooting-star was a small body, of unknown size, perhaps not larger than a pebble or a grain of coarse sand even, undoubtedly solid, which has been travelling around the sun in its own independent orbit, like any planet or comet. Its path came within 4000 miles of the earth's centre, and so the small body struck into the earth's atmosphere. Its velocity was so great fifty or a hundred times that of a cannon-ball - that even in our rare upper atmosphere an intense light and heat was developed by the resistance, and the body was scattered in powder or smoke. These bodies before they come into the air, I call meteoroids. It is only when they have reached our atmosphere and begin to burn that we ever see them. They are then within 90 miles of the ground.

(To be continued.)

\section{ON THE COAGULATION OF BLOOD'}

$\mathrm{B}^{\mathrm{R}}$

UUCKE'S researches on the conditions of coagulation of blood have shown that, on the one hand, contact with foreign bodies makes blood coagulate, and, on the other, that contact on all sides with the fresh vascular wall obviates coagulation (Durante). Lacker has proved the influence of foreign bodies on blood-coagulation by microscopic observation of coagulation in its first stages. In partial contradiction to these results was the observation of Grünhagen that blood, when received into glycerine, and so long as it did not mix, remained liquid. To determine the nature of these influences the following experiments were made. Blood was drawn under oil from the carotid artery of a dog, and let stand at ordinary indoortemperature; after twenty-four hours it was not coagulated. Then the blood was drawn into a vessel smeared inside with vaseline, and it too did not coagulate. When it was stirred with an oiled glass rod, no fibrin was separated; but when, even after several hours, part of

${ }^{x}$ By Ernst Freund, in Wiener medicinisize fahriüihth, r885, Heft $\mathrm{r}$. this blood was poured into an ungreased vessel, it coagulated in a few minutes. Moreover, contact with an ungreased glass rod sufficed to make the blood in the greased vessel coagulate outwards from the rod.

Further experiments showed that the drying of the upper layers of the blood, and the presence of small quantities of dust, caused coagulation even in the greased vessel; if this was guarded against, the blood remained liquid for days, and the corpuscles sank to the bottom, the plasma remaining as a clear liquid above.

After pouring out the blood, the greased walls of the glass vessel showed neither blood-colouring matters, nor traces of a separated albuminous body. A repetition of these experiments at $37^{\circ} \mathrm{C}$. gave the same result. In all the experiments blood was also, for comparison, drawn off into ungreased vessels, and in all these it coagulated, at the most, in a quarter of an hour.

In further experiments a small vaseline-lined glass tube was used as a canula; and the blood drawn through this into vaseline-lined vessels also remained uncoagulated.

When the outer orifice of a canula inserted in the carotid was closed, the blood column in it pulsated, without showing the least sign of coagulation even after two hours.

In all these experiments there was nowhere in the vessels with which the blood came into contact even a point for adhesion-such a point would have caused in shorter or longer time coagulation of the whole mass of blood. Thus the coagulative influence of foreign bodies appears to be due to their adhesion.

But to demonstrate that the anti-coagulative property of the vascular walls is due to the lack of adhesion, a further series of experiments was made with soaked fishbladders and parchment-tubes.

The membranes lay several hours in 0.6 per cent. chloride of sodium solution; the blood was drawn off through a vaseline-lined canula into the bladders and tubes, which were then so hung in a litre of the saltsolution that the mass of blood was under the surface. In these experiments also the blood remained liquid, the surrounding salt-solution having no coagulative effect, while some of the blood, poured after twenty-four hours into an ungreased porcelain vessel for comparison, soon coagulated. Like the blood-vessels, which, unlike manufactured vessels, after being emptied of the blood, retain no colouring-matter, the membranes, even after several days, showed neither imbibition with blood-colouring matter, nor any trace of coagulated fibrine. Thus, by soaking in salt-solution, a property of the blood-vessels was imparted to the fish-bladders and parchment-tubes.

It can hardly be doubted, then, that while, on the one hand, lack of adhesion prevents blood from coagulating, so, on the other, the presence of adhesion gives the impulse to coagulation.

\section{INOCULATION AS A PRESERVATIVE AGAINST CONSUMPTION}

M VERNEUIL has lately published a letter to the $\mathrm{N}$. editor of the Gazette hebdominaire, M. Lereboullet, in which he proposes to set on foot an experimental inquiry into the possibility of finding some method of "attenuating" the presumed virus of tubercle, so as to make inoculation therewith practically useful against consumption, either as a prophylactic measure, like vaccination against small-pox, or as a means of cure, like Pasteur's inoculations in hydrophobia.

Three thousand francs have already been subscribed, and the respectable names of Cornil, Bouchard, Damaschino, and Potain are mentioned among those who approve of the investigation.

It must however be remembered (I) that with the exception of hydrophobia, an exception still on trial, no human disease but small-pox is known which can be prevented by inoculation; (2) that of epizootic diseases 